\title{
Synthesis, Physicochemical Characterization and Structure Determination of Some Novel Nickel (II) Complexes
}

\author{
M. L. Harikumaran Nair ${ }^{1}$, K. P Lalitha ${ }^{1}$ \\ ${ }^{1}$ (Department of Chemistry, University College, Thiruvananthapuram, Kerala/University of Kerala, India)
}

\begin{abstract}
Some novel nickel(II) complexes with the ligand (z)-4-((2-hydroxy-3methoxyphenyl)diazenyl)-1,5-dimethyl-2-phenyl-1H-pyrazol-3-(2H)-one,GAAP,guiacolazoantipyrine, $\quad L$ having molecular formulae $\left[\mathrm{Ni}(\mathrm{L})_{2} \mathrm{X}_{2}\right]$ and $\left[\mathrm{Ni}(\mathrm{L})_{2}(\mathrm{NCS}) \mathrm{Cl}\right]$ where $\mathrm{X}=\mathrm{Cl}, \mathrm{Br}, \mathrm{NO}_{3}$ were synthesized and characterized. The elemental analysis, Spectral (IR, UV-Visible, EPR, FAB - mass) studies and thermo gravimetric analysis reveals that the Ni(II) is six coordinated in its complexes. A rhombic symmetry can be tentatively proposed for the complexes. The magnetic susceptibility measurements show that the complexes are paramagnetic in nature. The powder XRD study shows its anisotropic nature.
\end{abstract}

Keywords : nickel(II), azo dyes, EPR, FAB - mass

\section{Introduction}

Nickel is recognized as an essential trace element for bacteria, plants and animals. It exhibits $+3,+2$ and +1 oxidation states with various ligands in its complexes. Nickel(II) ion has a $\mathrm{d}^{8}$ electronic configuration. It forms a large number of complexes with wide range of geometries such as six coordinate octahedral (Oh), five coordinate pyramidal $\left(\mathrm{C}_{4 \mathrm{~V}}\right)$ or trigonal bipyramidal $\left(\mathrm{D}_{3 \mathrm{~h}}\right)$ and four coordinate square planar $\left(\mathrm{D}_{4 \mathrm{~h}}\right)$ or tetrahedral (Td) [1]. Azo pyrazolones are used most widely as dyes for textiles and other materials, in the analytical chemistry of metals and as medical drugs. In view of these we have prepared and characterized a few new complexes of nickel(II) with the potential multidentate ligand (z)-4-((2-hydroxy-3-methoxyphenyl)diazenyl)1,5-dimethyl-2-phenyl-1H-pyrazol-3-(2H)-one,GAAP, guiacolazoantipyrine, L.

\section{Experimental}

4-Aminoantipyrine (Fluka, Switzerland), Guaiacol (2-methoxyphenol) (Lobochemie, Mumbai) were used as supplied. All other chemicals including nickel(II) carbonate were of A.R. grade.

\subsection{Synthesis of the Ligand}

The ligand GAAP, L was synthesized by diazotization of 4-aminoantipyrine followed by coupling with 2-methoxy phenol (guiacol) below $5^{\circ} \mathrm{C}$, washed with cold water, dried and kept in a desiccator [2].

\subsection{Synthesis of the Complexes}

Hot methanolic solution $(30 \mathrm{~mL}, 2.5 \mathrm{mmol})$ of the metal salt was added with constant stirring to a hot solution of the ligand (30 mL, $2.5 \mathrm{mmol})$ in an RB flask, refluxed for (4-6) $\mathrm{h}$, transferred into a beaker, crystallized by slow evaporation, washed with aqueous methanol, benzene and finally with ether, dried and kept in a desiccator (yield $65 \%$ ).

\subsection{Physical measurements}

The metal, halogen and perchlorate were estimated by standard method[3]. Microanalysis (CHNS) were performed on VarioEL III CHNS Elemental Analyzer.

The IR spectra of the ligand and its nickel(II) complexes were recorded in the region, $4000-400 \mathrm{~cm}-1$ on JASCO FTIR 430 and on SHIMADZU spectrophotometers using KBr pellets. The 1H NMR spectra of the ligand was recorded in $\mathrm{CD}_{3} \mathrm{OD}$ on a $300 \mathrm{MHz}$ (Bruker Advance dPx-300) FTNMR instrument using TMS as reference. The electronic spectra were recorded in the solid state by reflectance method on a Varian Cary $5 \mathrm{E}$ UV-Vis-NIR spectrometer.

Magnetic susceptibilities of the complexes at room temperature $(300 \pm 3 \mathrm{~K})$ were measured on a magnetic susceptibility balance, Sherwood Scientific, Cambridge, UK. Diamagnetic corrections $(\chi$ Dia) for various atoms and structural units were computed using Pascal constants. Thermal analysis of the complex $\left[\mathrm{Ni}(\mathrm{L})_{2}\left(\mathrm{NO}_{3}\right)_{2}\right]$ was carried on Perkin Elmer Diamond TG/DTA.

X-ray powder diffraction patterns of the complex $\left[\mathrm{Ni}(\mathrm{L})_{2}\left(\mathrm{NO}_{3}\right)_{2}\right]$ was also carried out on Philips X-ray diffractometer (PW1710) using k $\alpha$ radiation with $\lambda=1.5405 \AA$ and was indexed using Hesse and Lipson's procedure. 
The X-band EPR spectrum of the complexes in the polycrystalline state and in DMSO was studied at room temperature at $9.1 \mathrm{GHz}$ microwave frequency using TCNE $(\mathrm{g}=2.0027)$ as standard on Varian E- 112.

\subsection{Analytical measurements and magnetic susceptibilities}

\section{Results And Discussion}

All the complexes are dark colored, non-hygroscopic solids and nonelectrolytes (Table 1) [4]. They are soluble in nitrobenzene and acetonitrile and sparingly soluble in other organic solvents.

TABLE 1. Analytical and Physical Data of GAAP, L and Ni(II) Complexes

\begin{tabular}{|c|c|c|c|c|c|c|c|c|}
\hline \multirow{2}{*}{ Ligand /Complex } & \multicolumn{6}{|c|}{ Analytical data (\%): Found (calcd.) } & \multirow{2}{*}{$\begin{array}{c}\text { Molar conductance in } \\
\text { Nitrobenzene } \Omega^{-1} \mathrm{~cm}^{2} \\
\text { mol }^{-1}\end{array}$} & \multirow{2}{*}{$\begin{array}{c}\mu_{\text {eff }} \\
\mu \mathrm{B} .\end{array}$} \\
\hline & Metal & $\mathrm{Cl} / \mathrm{Br}$ & $\mathrm{C}$ & $\mathbf{H}$ & $\mathbf{N}$ & $\mathbf{S}$ & & \\
\hline GAAP, L & - & - & $\begin{array}{c}63.6 \\
(63.9)\end{array}$ & $\begin{array}{c}5.3 \\
(5.3)\end{array}$ & $\begin{array}{c}16.5 \\
(16.5)\end{array}$ & - & - & - \\
\hline$\left[\mathrm{Ni}(\mathrm{L})_{2} \mathrm{Cl}_{2}\right]$ & $\begin{array}{l}7.1 \\
(7.2)\end{array}$ & $\begin{array}{c}8.8 \\
(8.8)\end{array}$ & $\begin{array}{c}53.6 \\
(53.8)\end{array}$ & $\begin{array}{l}4.4 \\
(4.4)\end{array}$ & $\begin{array}{c}13.8 \\
(13.9)\end{array}$ & - & 1.1 & 3.4 \\
\hline$\left[\mathrm{Ni}(\mathrm{L})_{2}(\mathrm{NCS}) \mathrm{Cl}\right]$ & $\begin{array}{l}6.9 \\
(7.0)\end{array}$ & $\begin{array}{c}41 \\
(4.2 \\
0\end{array}$ & $\begin{array}{c}53.6 \\
(53.8)\end{array}$ & $\begin{array}{l}4.3 \\
(4.3)\end{array}$ & $\begin{array}{c}15.3 \\
(15.2)\end{array}$ & $\begin{array}{c}6.9 \\
(6.8)\end{array}$ & 1.5 & 3.4 \\
\hline$\left[\mathrm{Ni}(\mathrm{L})_{2}\left(\mathrm{Br}_{2}\right]\right.$ & $\begin{array}{c}6.5 \\
(6.5)\end{array}$ & $\begin{array}{c}17.7 \\
(17.8)\end{array}$ & $\begin{array}{c}48.0 \\
(48.2)\end{array}$ & $\begin{array}{l}4.1 \\
(4.0)\end{array}$ & $\begin{array}{c}12.6 \\
(12.5)\end{array}$ & & 1.5 & 3.4 \\
\hline$\left[\mathrm{Ni}(\mathrm{L})_{2}\left(\mathrm{NO}_{3}\right)_{2}\right]$ & $\begin{array}{c}6.7 \\
(6.8)\end{array}$ & & $\begin{array}{c}50.2 \\
(50.3)\end{array}$ & $\begin{array}{c}4.1 \\
(4.1)\end{array}$ & $\begin{array}{c}16.4 \\
(16.3)\end{array}$ & & 1.3 & 3.4 \\
\hline
\end{tabular}

The magnetic susceptibility measurement shows that the magnetic moments of the complexes are much greater than that of the pure octahedral complexes may be due to spin orbit coupling confirming that they are paramagnetic[5] and distortion from octahedral geometry. Diamagnetic corrections[6], $\chi_{\text {Dia }}$ were computed using Pascal's constants $\left(\chi_{\text {Dia }}=-12.8 \times 10^{-6}\right.$ C.G.S. units for $\left.\mathrm{Ni}^{2+}\right)$.

\subsection{Spectral Characterization}

\subsubsection{The ${ }^{1} \mathrm{H}$ NMR spectrum}

The ${ }^{1} \mathrm{H}$ NMR spectrum of the ligand GAAP, L shows three singlets[7] at $\delta(2.7-2.98) \mathrm{ppm}, \delta(3.05-$ 3.39) $\mathrm{ppm}$ and $\delta(3.83-3.91) \mathrm{ppm}$ corresponds to methyl protons of $>\mathrm{C}-\mathrm{CH}_{3},>\mathrm{N}-\mathrm{CH}_{3}$ and $-\mathrm{OCH}_{3}$ respectively. The signal due to five aromatic protons of the antipyrine phenyl ring appear as multiplet between $\delta$ (7.38-7.59) ppm and those due to protons of phenyl ring of phenol moiety are observed as multiplet between $\delta$ $(6.85-6.88) \mathrm{ppm}$. The signal due to phenolic -OH proton appears as a hump[7] at $\delta 5.56 \mathrm{ppm}$.

\subsubsection{Infra Red spectrum}

The infra-red spectrum of the ligand possess a broad band of medium intensity $\sim 3103 \mathrm{~cm}^{-1}$ is assignable to hydrogen bonded $-\mathrm{OH}$ group[8]. This band is replaced by a new band $\sim 3400 \mathrm{~cm}^{-1}$ indicating the non-participation of the $-\mathrm{OH}$ group in the complex formation[9]. The $\mathrm{C}=\mathrm{O}$ stretching frequency occurring at $1637 \mathrm{~cm}^{-1}$ in the spectrum of the ligand shows a downward shift to $(1612-1568) \mathrm{cm}^{-1}$ in all the complexes showing the evidence of participation of $\mathrm{C}=\mathrm{O}$ group in complexation[10]. Similarly a band of medium intensity observed $\sim 1458 \mathrm{~cm}^{-1}$ in the spectrum of the ligand shows a red shift to $\sim(1427-1419) \mathrm{cm}^{-1}$ in the spectra of all the complexes is suggesting the participation of azo group in coordination[11] with the metal ion. The evidences suggest the neutral bidentate nature of the ligand in all the complexes.

The nitrato complex shows bands at $1505 \mathrm{~cm}^{-1}, 1388 \mathrm{~cm}^{-1}$ and $1024 \mathrm{~cm}^{-1}$ assignable to $v_{4}, v_{1}$ and $v_{2}$ modes respectively of unidentately coordinated nitrate[12] group. The $\mathrm{N}$ - coordinated nature of the thiocyanate group in its complex is indicated by $v_{\mathrm{C}-\mathrm{N}}\left(\sim 2061 \mathrm{~cm}^{-1}\right), v_{\mathrm{C}-\mathrm{S}}\left(\sim 765 \mathrm{~cm}^{-1}\right)$ and $\delta_{\mathrm{NCS}}\left(\sim 470 \mathrm{~cm}^{-1}\right)$.

\subsubsection{Electronic Spectra}

The electronic spectrum of the ligand shows an intense band at $380 \mathrm{~nm}$ is attributed to $\mathrm{n} \rightarrow \pi^{*}$ transition. The electronic spectra of the present complexes are similar and characterized by absorption band $380 \mathrm{~nm}$ and $\sim 600 \mathrm{~nm}$ is characteristics of square planar complexes. This may be [13] attributed to $\mathrm{a}_{1 \mathrm{~g}} \rightarrow \mathrm{b}_{1 \mathrm{~g}}$ and $b_{2 \mathrm{~g}} \rightarrow b_{1 \mathrm{~g}}$ transitions. 


\subsubsection{EPR Spectra of Complexes}

The X-band EPR spectrum [14] of the complex $\left[\mathrm{Ni}(\mathrm{L})_{2} \mathrm{Br}_{2}\right]$ in the polycrystalline state at room temperature (Fig. 1) and also that of liquid nitrogen temperature exhibited a single and very broad line and the peak from TCNE (which is the standard) is completely masking and the g value may be 2.005 indicating highly distorted octahedral system. The X- band EPR spectrum [14] of the complex $\left[\mathrm{Ni}(\mathrm{L})_{2}(\mathrm{NCS}) \mathrm{Cl}\right]$ in DMSO at liquid nitrogen temperature (Fig. 2) reveals that this is $\mathrm{Ni}(\mathrm{II}) \mathrm{d}^{8}$ system which has square planar structure which is very much distorted from octahedral symmetry. Along with this there is strong spin orbit coupling and zero field splitting which results in the charge deviation of the $\mathrm{g}$ - value, 4.230 from the free electron value $\mathrm{g}$ - value of 2.002316. Also it is possible that the nickel(II) complex is in the rhombic symmetry.

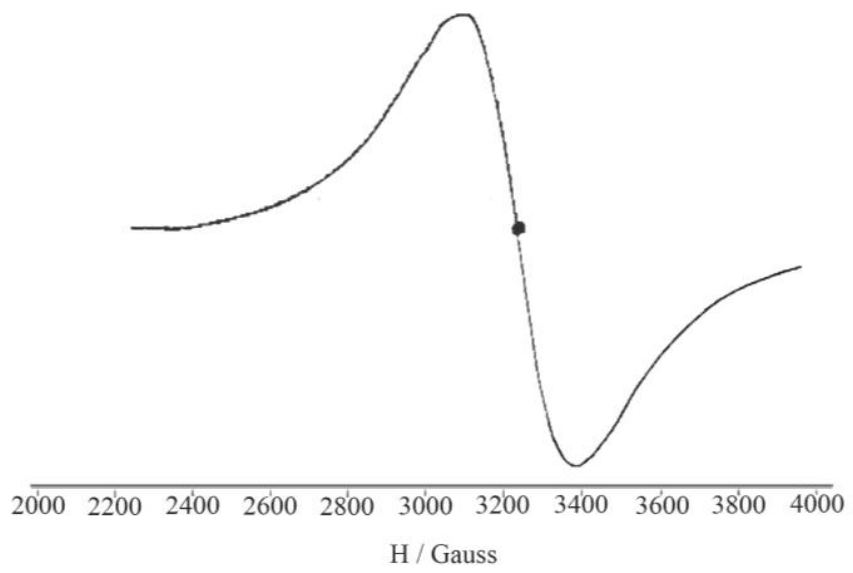

Fig.1. The EPR Spectrum of $\left[\mathrm{Ni}(\mathrm{L})_{2} \mathrm{Br}_{2}\right]$

\subsubsection{FAB - mass Spectrum}

The molecular ion peak at $\mathrm{m} / \mathrm{z}=806.59$ is absent in the spectrum of $\left[\mathrm{Ni}(\mathrm{L})_{2} \mathrm{Cl}_{2}\right]$ (Fig. 3), instead the ion peak at $\mathrm{m} / \mathrm{z}=736.6,\left[\left(\mathrm{C}_{18} \mathrm{H}_{18} \mathrm{~N}_{4} \mathrm{O}_{3}\right)_{2} \mathrm{Ni}\right]^{+}$, (obtained after the removal of two chlorine atoms in conformity with TG (Fig. 4). The absence of molecular ion peak at $\mathrm{m} / \mathrm{z}=806.59$ may due to its highly distorted six coordinated structure. The other important peaks are due to [15] the formation of $\mathrm{m} / \mathrm{z}=381.49,\left[\left(\mathrm{C}_{17} \mathrm{H}_{15} \mathrm{~N}_{4} \mathrm{O}_{3}\right)\right.$ $\mathrm{Ni}]^{+}$, the base peak; $\mathrm{m} / \mathrm{z}=411.69$, for $\left[\left(\mathrm{C}_{18} \mathrm{H}_{18} \mathrm{~N}_{4} \mathrm{O}_{3}\right) \mathrm{NiN}\right]^{+} ; \mathrm{m} / \mathrm{z}=395.62$, for $\left[\left(\mathrm{C}_{18} \mathrm{H}_{15} \mathrm{~N}_{4} \mathrm{O}_{3}\right) \mathrm{NiN}\right]^{+} ; \mathrm{m} / \mathrm{z}=$ 197.36, for $\left[\left(\mathrm{C}_{5} \mathrm{H}_{6} \mathrm{~N}_{4} \mathrm{O}_{3}\right) \mathrm{Ni}\right]^{+} ; \mathrm{m} / \mathrm{z}=181.34$, for $\left[\left(\mathrm{C}_{4} \mathrm{H}_{3} \mathrm{~N}_{4} \mathrm{O}_{3}\right) \mathrm{Ni}\right]^{+}$and $\mathrm{m} / \mathrm{z}=109.24$, for $\left[\left(\mathrm{C}_{2} \mathrm{~N}_{2}\right) \mathrm{Ni}\right]^{+}$. The other important peaks are due to the formation of various radicals such as $\left(\mathrm{C}_{7} \mathrm{H}_{7} \mathrm{O}_{2} \cdot\right),(\mathrm{m} / \mathrm{z}=123)$; $\left(\mathrm{C}_{11} \mathrm{H}_{11} \mathrm{~N}_{4} \mathrm{O} \cdot\right),(\mathrm{m} / \mathrm{z}=215) ;\left(\mathrm{C}_{18} \mathrm{H}_{18} \mathrm{~N}_{4} \mathrm{O}_{3} \cdot\right),(\mathrm{m} / \mathrm{z}=339) ;\left(\mathrm{C}_{6} \mathrm{H}_{5} \mathrm{~N}_{2}\left(\mathrm{CH}_{3}\right) \mathrm{CO} \cdot\right),(\mathrm{m} / \mathrm{z}=149)$; and for $\left(\mathrm{N}^{\cdot}\right),\left(\mathrm{CH}_{3} \cdot\right)$, $\left(\mathrm{C}_{6} \mathrm{H}_{4} \mathrm{O} \cdot\right),\left(\mathrm{C}_{6} \mathrm{H}_{5} \cdot\right)$, and $\left(\mathrm{N}_{2} \mathrm{CO} \cdot\right)$.

\subsection{Thermo gravimetric Analysis}

Thermal behavior of the complex $\left[\mathrm{Ni}(\mathrm{L})_{2}\left(\mathrm{NO}_{3}\right)_{2}\right]$ was studied by TGA in air at a heating rate of $10^{\circ}$ $\mathrm{Kmin}^{-1}$ in conjunction with DTG (Fig. 5). The complex undergoes a three stages[16] decomposition as indicated by DTG peaks at $508 \mathrm{~K}, 643 \mathrm{~K}$ and $688 \mathrm{~K}$.

The TG curve shows a second plateau after $733 \mathrm{~K}$. This indicates completion of the decomposition[17]. The first stage of decomposition initiates at $373 \mathrm{~K}$ and occurs at $(393 \mathrm{~K}-513 \mathrm{~K})$ is due to the mass loss of two nitrate moiety, making mass loss of $14.43 \%$. The decomposition continues with a gradual decrease in weight and at $(518 \mathrm{~K}-663 \mathrm{~K})$ with a mass loss of $43.48 \%$ is due to the mass loss of one ligand moiety and a part of the second ligand moiety. The third stage of decomposition occurs at $(668 \mathrm{~K}-698 \mathrm{~K})$ is due to the mass loss of the remaining part of the ligand moiety, making a mass loss of $35.30 \%$ and it is finally undergone oxidative decomposition[18] to $\mathrm{NiO}$. The residual mass is about $8.66 \%$ (theoretical $-8.69 \%$ ) which has been assigned to the oxidative decomposition to give $\mathrm{NiO}$ as the ultimate residue. 

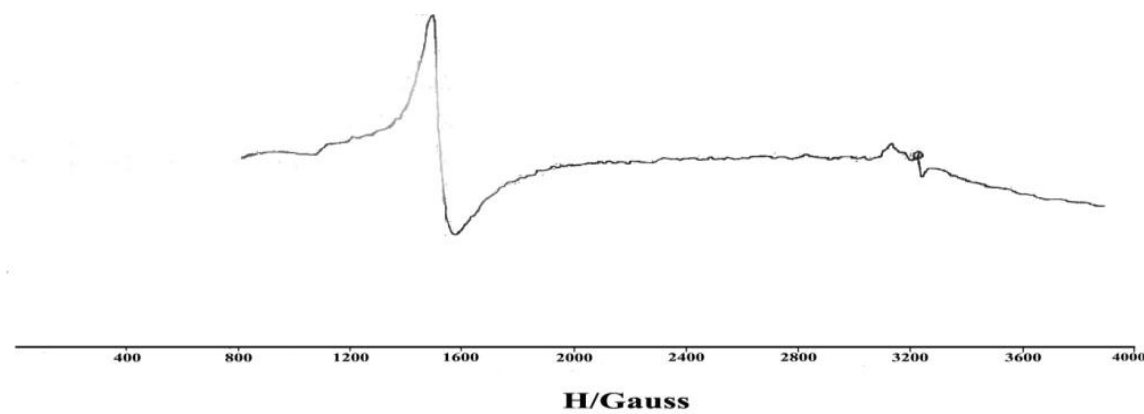

Fig. 2. The EPR Spectrum of $\left[\mathrm{Ni}(\mathrm{L})_{2}(\mathrm{NCS}) \mathrm{Cl}\right]$

TABLE 2. Decomposition parameters of $\left[\mathrm{Ni}(\mathrm{L})_{2}\left(\mathrm{NO}_{3}\right)_{2}\right]$

\begin{tabular}{|l|l|l|l|l|}
\hline Decomposition stages & \multicolumn{1}{|c|}{ Order } & \multicolumn{1}{c|}{$\begin{array}{c}\text { Correlation } \\
\text { coefficient } ®\end{array}$} & \multirow{2}{*}{$\mathrm{Ea}\left(\mathrm{JK}^{-1} \mathrm{~mol}^{-1}\right)$} & \\
\cline { 1 - 3 } & 1.5 & 0.9917 & -17.6 & 132.5 \\
\hline Stage 1 & 2.0 & 0.9972 & 237.6 & 319.2 \\
\hline Stage 2 & 2.0 & 0.9995 & 55.1 & 227.6 \\
\hline
\end{tabular}

The three decomposition stages obey Coats-Redfern equation [19]. The correlation coefficient R, entropy changes $\Delta \mathrm{S}$, activation energy Ea for the three stages of decomposition are given in (Table 2). The negative $\Delta \mathrm{S}$ value $-17.6 \mathrm{JK}^{-1} \mathrm{~mol}^{-1}$ for the stage 1 suggests the instability of the decomposition stage. The negative $\Delta \mathrm{S}$ value also indicates that the activated complex has more ordered structure than the reactants and the reactions are slower than the normal[20].

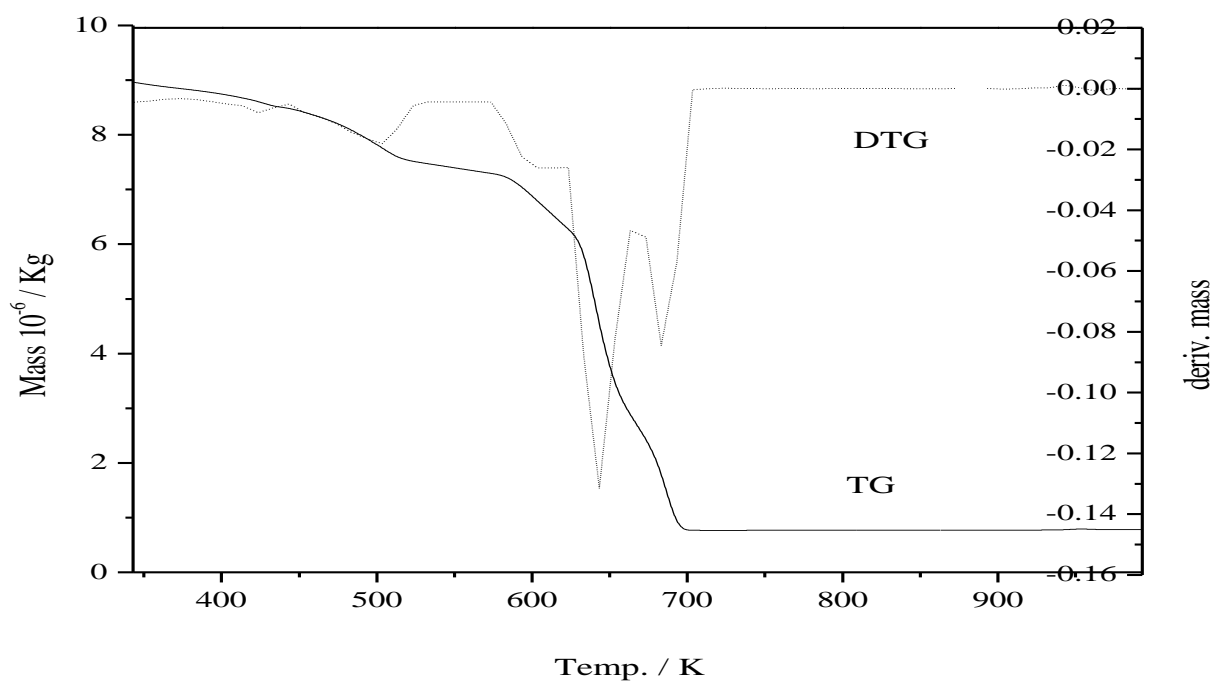

Fig. 4. TG \& DTG curve $\left[\mathrm{Ni}(\mathrm{L})_{2}\left(\mathrm{NO}_{3}\right)_{2}\right]$

\subsection{X- ray diffraction Studies}

X-ray powder diffraction patterns (Fig.5) of the complex $\left[\mathrm{Ni}\left(\mathrm{L}_{2}\left(\mathrm{NO}_{3}\right)_{2}\right]\right.$ has been carried out using K $\alpha$ radiation with $\lambda=1.5405 \AA$ and was indexed using Hesse and Lipson's procedure[21]. The results show that the complex belongs to the orthorhombic crystal system having unit cell dimensions, $a=7.683 \AA, b=5.741 \AA$ and $c=$ 8.611А. 


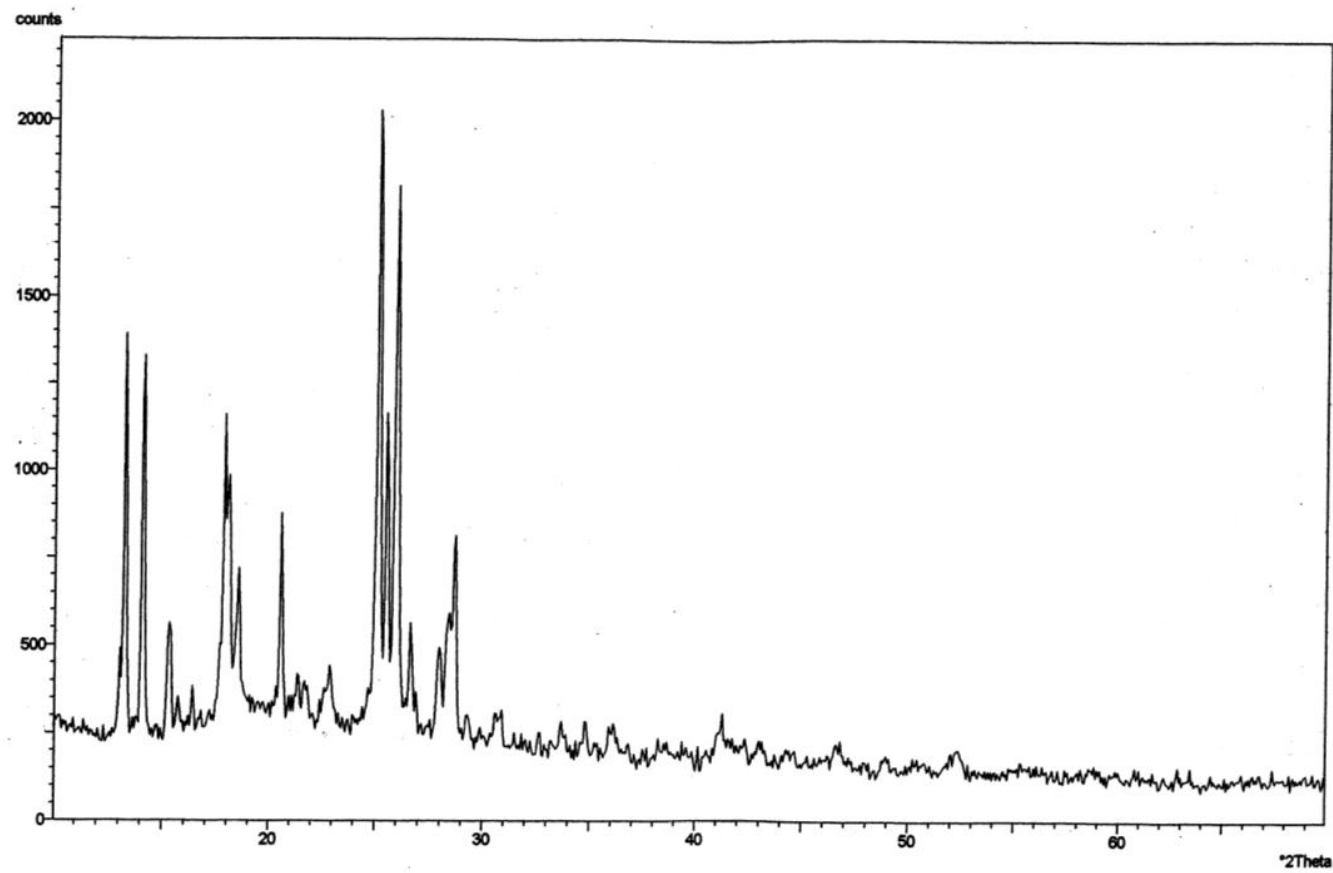

Fig.5. X-ray diffraction pattern of $\left[\mathrm{Ni}(\mathrm{L})_{2}\left(\mathrm{NO}_{3}\right)_{2}\right]$

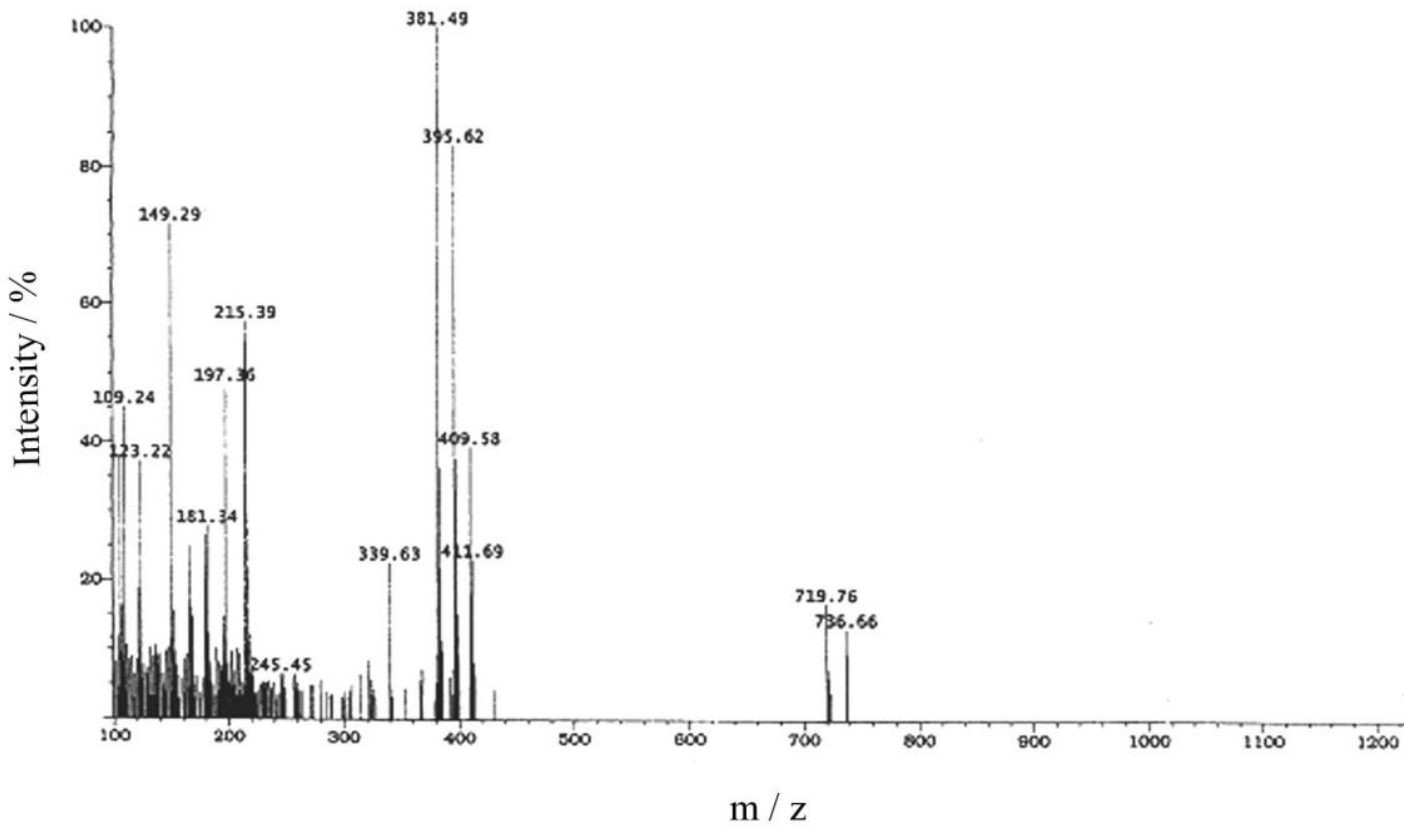

Fig. 3. FAB-mass spectrum of $\left[\mathrm{Ni}(\mathrm{L})_{2} \mathrm{Cl}_{2}\right]$

\section{Conclusion}

The ligand GAAP, L behaved as neutral bidentate in nature and nickel(II) with $\mathrm{d}^{8}$ system is having six coordination in its complexes which possess rhombic symmetry

\section{Acknowledgements}

The authors are thankful to NIIST, Thiruvananthapuram, Kerala, India; SAIF, IIT, Chennai, India; SAIF, STIC, Cochin, Kerala, India; Dept. of Chemistry, University of Kerala, Thiruvananthapuram, Kerala, India for extending their facilities for conducting part of the studies. 


\section{References}

[1] F. A. Cotton and G. Wilkinson, Advanced inorganic chemistry, $6^{\text {th }}$ ed. (New Delhi : Wiley Eastern, 1999).

[2] C. Mercy Raj, Studies on some thiocyanates and selenocyanates complexes, doctoral diss.,University of Kerala, India, 1992.

[3] A.I. Voge, A Text book of quantitative chemical analysis, $5^{\text {th }}$ ed. (ELBS with Longman, 1996) 461

[4] K.Ueno and A. E. Martell, Journal of Physical Chemistry, 60, 1956, 1270

[5] D. Nicholls, Comprehensive inorganic chemistry ((Ed.) Bailar Jr., 3 (J. C. Pergamon press, 1973$) 1109$.

[6] R. L. Dutta and A. Syamal, Elements of magneto chemistry, $2^{\text {nd }}$ ed. (New Delhi: : East-West Press, 2007).

[7] M. L. Harikumaran Nair, George Mathew and M. R. Sudarsana Kumar, Indian Journal of Chemistry, 44A, $2005,87$.

[8] M. L. Harikumaran Nair and L. Shamla, Journal of Indian Chemical Society, 86, 2009, 137.

[9] M. L. Harikumaran Nair, M. S. Pramila Gladis and A. Sheela, Journal of Indian Chemical Society, 84, 2007, 861-862

[10] K. Nakamoto, Infrared and raman spectra of inorganic and coordination compounds, $3^{\text {rd }}$ ed.( New York : Wiley, 1978).

[11] M. L. Harikumaran Nair and A. T. Mariamma, Journal of Indian Chemical Society, 88, 2011, 765-773.

[12] M. L. Harikumaran Nair and V. L. Siji, Journal of Indian Chemical Society, 86, 2009, 441-448.

[13] R. L. Carlin, Transition metal chemistry (New York :Marcel Dekker Inc., 1968).

[14] J. E. Wertz, and J. R. Bolton, Electron spin resonance: elementary theory and practical applications (USA : McGraw-Hill, 1972)199.

[15] R. K. Dubey, U. K. Dubey and C. M. Mishra, Indian Journal of Chemistry 45A, 2006, 2632-2637.

[16] W. W. M. Wendlandt, The properties of transition-metal ammine complexes (New York: Elsevier Publishing Company, 1967).

[17] R. Thomas, K. J. Thomas and G. Parameshwaran, Journal of Indian Chemical Society 73, 1996, 529.

[18] K. Krishnan, K.N. Ninan and P. M. Madhusudanan, Thermo Chimica Acta., 140, 1989, 325.

[19] A. Kilic, E. Tas and I.Yilmaz, Journal of Chemical Science 121(1), 2009, 43-56.

[20] M. L. Harikumaran Nair and D. Thankamani, Indian Journal Chemistry, 48A, 2009, 1212-1218.

[21] R. Hesse, Acta Crystallog., 1, 1948, 200. 